\title{
APROXIMACIÓN AL TRATAMIENTO LEXICOGRÁFICO DE LOS VERBOS DE CAMBIO EN TRES DICCIONARIOS GENERALES DEL ESPAÑOL
}


Esta pequeña aportación filológica pretende acercarse al tratamiento lexicográfico que reciben los denominados 'verbos de cambio de estado' - siguiendo la terminología de autores como Porroche (1994) o Coronado (1994), entre otros- en tres diccionarios generales del español, como son el Diccionario de la lengua española, de la Real Academia Española, el Diccionario de uso del español, de María Moliner y el Diccionario 'Coruña' de la lengua española, dirigido por el profesor Porto Dapena. ${ }^{1}$ Se trata de analizar cuáles son los criterios lexicográficos que siguen estos diccionarios generales del español a la hora de reflejar la peculiaridad constructiva que singulariza a este tipo de verbos.

Palabras clave: lexicografía, verbos de cambio

This contribution is an approach to the treatment that receives a lexical class of verbs, called 'change of state verbs' in three general dictionaries of Spanish, such as the Diccionario de la lengua española, of the Real Academia Española, the Diccionario de uso del español, of María Moliner and the Diccionario 'Coruña' de la lengua española, led by Professor Porto Dapena. We analyze the lexicographical criteria that follow these general dictionaries of Spanish when reflect the constructive peculiarity that distinguishes this type of verbs.

KEY wORDs: lexicography, verbs of change

RECEPCIÓN: 31/05/2015

ACEPTACIÓN: 10/07/2015

\footnotetext{
${ }^{1}$ Para obtener un análisis del tratamiento lexicográfico de los verbos de cambio con valor pseudo-copulativo en cinco diccionarios didácticos del español, véase Oreal (2008).
} 


\title{
APROXIMACIÓN AL TRATAMIENTO LEXICOGRÁFICO DE LOS VERBOS DE CAMBIO EN TRES DICCIONARIOS GENERALES DEL ESPAÑOL
}

\author{
María Eugenia Conde Noguerol \\ Grupo de Investigación en Lengua, Literatura y Cultura \\ Hispánica (Hispania) / Universidade da Coruña
}

\section{Introducción y objetivos}

Con verbos de cambio nos referimos a un subconjunto de verbos que, por un lado, son capaces de expresar el cambio, el devenir o la transformación de una entidad y, por otro, presentan unas determinadas peculiaridades sintácticosemánticas, ya que casi en su totalidad ${ }^{2}$ se integran en un doble esquema sintáctico, transitivo e intransitivo y/o pronominal, tal y como vemos en los ejemplos de 1 :

1. a. El ejercicio adelgaza a las personas

1. b. Las personas adelgazan con el ejercicio

\footnotetext{
${ }^{2}$ Con salvadas excepciones, como crecer o medrar, que solo presentan variedad intransitiva; o machacar o triturar, que solo poseen variedad transitiva.
} 


\section{1. c. La levadura avinagra el vino \\ 1.d. El vino se avinagra con la levadura}

Como se observa, se trata de verbos que pueden funcionar como predicados de construcciones transitivas con sentido causativo (1.a. y 1.c.) y de construcciones intransitivas, generalmente pronominales con sentido medio (1.b. y 1.d.), con un sujeto (las personas y el vino) que se corresponde con el complemento directo de aquellas; es decir, participan de la doble construcción, transitiva e intransitiva, con la consiguiente variación semántica. ${ }^{3}$

Se trata, entonces, de abordar cuáles son los criterios lexicográficos que tienen algunos diccionarios generales del español a la hora de reflejar la peculiaridad constructiva que caracteriza a este tipo de verbos, propiedad sobre la que ya incide Rufino José Cuervo (1953: 5) en su Diccionario de construcción y régimen, poniendo de manifiesto la necesidad de que todo lexicógrafo informe al registrar los empleos transitivos e intransitivos de cada verbo de la variación que se produce al pasar "del sentido intransitivo al factitivo ó causativo, como cuando se dice andar por hacer andar ó mover, entrar por hacer entrar ó poner dentro, subir por hacer subir ó poner arriba".

Nos encontramos, pues, ante una serie de verbos que cuando alteran su estructura sintáctica sufren una modificación semántica de la que sería necesario advertir en los diccionarios generales. Sin embargo, la realidad nos demues-

\footnotetext{
${ }^{3}$ Véase Conde (2015) para un acercamiento analítico a la estructura argumental de los verbos de cambio de estado para su tratamiento lexicográfico.
} 
tra que la mayoría de diccionarios generales del español no reflejan estas variaciones, presentándonos estos verbos en definiciones que se corresponden con esquemas sintácticos comunes a otros verbos que no poseen el sema de cambio.

Para mostrar este aspecto, hemos analizado tres diccionarios generales del español: el Diccionario de la lengua española, de la Real Academia Española, el Diccionario de uso del español, de María Moliner, y el Diccionario 'Coruña' de la lengua española. Como comprobaremos, estas tres obras lexicográficas presentan diversos enfoques de tratamiento y alguna no llega a mostrar la peculiaridad sintáctico-semántica que caracteriza a estos verbos. ${ }^{4}$

Asimismo, para el análisis hemos seleccionado 11 verbos de cambio, elegidos de forma aleatoria, que son: adecentar, adelgazar, alegrar, amargar, ahumar, avinagrar, curar, embellecer, engordar, quebrar y templar.

\section{Diccionario de la lengua española (RAE)}

En primer lugar, al consultar estos verbos en el DRAE, ${ }^{4}$ advertimos que esta obra opta en la mayoría de los casos por añadir marcas gramaticales como u.m.c.prnl y u.t.c.prnl al final de la definición de la construcción transitiva, sin añadir ninguna

\footnotetext{
${ }^{4}$ En el caso del DRAE, Veleiro (2005) constata, tras analizar 70 verbos de cambio en la vigésimo primera edición, que los matices constructivos de estos verbos no se plasman suficientemente en esta obra, deficiencias que se siguen observando en la vigésimo tercera edición, pues estos verbos no han sufrido modificación alguna, tal y como se comprueba en verbos como curtir, adobar o entristecer, entre otros.
} 
modificación a la definición. De esto debemos deducir que esa construcción, se supone que con la misma definición, se usa también de forma pronominal. Este procedimiento es aplicado a verbos como adecentar (acepción 1), adelgazar (acepciones 1 y 2), amargar (acepciones 2 y 3), ahumar (acepción 2), avinagrar (acepción 1), curar (acepción 1), embellecer (acepción 1) y quebrar (acepciones 3 y 6). De este modo, el verbo curar aparece definido de la forma que sigue:

\section{Curar:}

1. Aplicar con éxito a un paciente los remedios correspondientes a la remisión de una lesión o dolencia. U. t. c. prnl.

Pensamos que, tal y como señala Veleiro (2005: 284), no hay una equivalencia exacta entre las dos definiciones, la correspondiente a la transitiva y la pronominal, puesto que "para que la acepción equivaliese con precisión a la construcción pronominal, se tendría que reelaborar su redacción" y esto no se lleva a cabo en el DRAE. Es evidente que la definición correspondiente a la construcción pronominal de curar no es ya 'aplicarse con éxito a un paciente los remedios correspondientes a la remisión de una lesión o dolencia', sino 'recobrar la salud', pero esta nueva información ha de ser deducida.

Es claro que al pasar de una construcción a otra se produce un cambio en el orden de los actantes que lleva implícito un cambio de sentido que no aparece expresado en la definición.

En otros casos, el DRAE recurre a presentar dos acepciones distintas, una para la construcción transitiva y otra para 
la pronominal o intransitiva, tal y como vemos con verbos como adelgazar (acepciones 1 y 6), amargar (acepciones 1 y 4), alegrar (acepciones 1 y 7), engordar (acepciones 1 y 2) y templar (acepciones 2 y 12). En la mayoría de los casos estas acepciones no se presentan de forma correlativa, por lo que no se evidencia la relación existente entre las dos acepciones, ya que no se refleja en ningún momento que el complemento directo de la construcción transitiva se corresponde con el sujeto de la pronominal. Este criterio definicional se aplica, por ejemplo, al verbo alegrar cuya acepción 1 se corresponde con la construcción transitiva, y la 7 con la construcción pronominal.

\section{Alegrar: \\ 1. tr. Causar alegría. \\ 7. prnl. Recibir o sentir alegría.}

En otras ocasiones, como en el caso de adelgazar, se recurre a presentar ambos procedimientos. Por un lado, se incluye la marca u.t.c.prnl al final de la definición correspondiente a la construcción transitiva (acepción 1) y, por otro, se añade una nueva acepción en la que se define la construcción intransitiva (acepción 6), y se le añade también la marca u.t.c.prnl.

\section{Adelgazar:}

1. tr. Reducir el grosor de un cuerpo, bien eliminando parte de su materia, bien sin pérdida de ella. U.t.c.prnl.

6. intr. Disminuir en grosor y generalmente en peso, ponerse delgado, enflaquecer. U.t.c.prnl. 
A la vista de lo hasta aquí mostrado, parece que el DRAE no presenta un criterio claro a la hora de tratar estas formas verbales, pues verbos que se comportan de forma semejante reciben tratamientos lexicográficos distintos.

\section{Diccionario de uso del español}

Por otro lado, si atendemos al tratamiento que reciben los verbos de cambio en el DUE, comprobamos que esta obra muestra de manera más evidente los matices semánticos propios de estos verbos. En este sentido, María Moliner opta mayoritariamente por considerar acepciones las definiciones relativas a la construcción transitiva $y$, como subacepciones, las referentes a la construcción pronominal o intransitiva, lo que le permite establecer relaciones entre unas y otras. Para ello, lleva a cabo la reelaboración de la acepción que se corresponde con la variante causativa adecuándola a la construcción pronominal, tal y como vemos en el ejemplo de curar (acepción 2):

\section{Curar:}

2. (“de, con”) tr. Poner bien a una persona o animal, a un organismo o a una parte de él que están enfermos: 'Estoy seguro de que ese médico me curará. $\mathrm{O}^{5}$ ("de, con") Hacer desaparecer cierta enfermedad: 'Estas pastillas curan la gripe. $\bigcirc$ (“de, con”) intr. y prnl. Ponerse bien alguien o algo que estaba enfermo: 'Tiene esperanza de que curará. Ya verás como curas enseguida. La herida se curó sola’.

\footnotetext{
${ }^{5}$ Los círculos introducen una subacepción.
} 
Este procedimiento se repite con verbos como ahumar (acepción 1), alegrar (acepción 1), amargar (acepción 3), curar (acepción 2), embellecer (acepción 1) y templar (acepción 3).

Ahora bien, se advierte cierta asistematicidad a la hora de abordar las definiciones. En algunos casos, como ahumar (acepción 1), curar (acepción 2) o templar (acepción 3 ), se introducen ejemplos de uso después de la definición que ayudan a esclarecerla y sirven de modelo constructivo, frente a otros en los que no aparecen, como en el caso de amargar (acepciones 1, 2 y 3) o embellecer (acepción 1). Asimismo, en algunas ocasiones se ejemplifican las entidades que funcionan como objeto directo y sujeto dentro del cuerpo de la definición, como ocurre con el verbo ahumar:

\section{Ahumar:}

1. tr. Llenar algo de humo; por ejemplo, una colmena. $\bigcirc$ prnl. Llenarse de humo, por ejemplo, una habitación.

Por otro lado, encontramos casos (por ejemplo, engordar, acepción 1) en los que se invierte el procedimiento y la acepción se corresponde con la construcción intransitiva y la subacepción con la transitiva: ${ }^{6}$

\footnotetext{
${ }^{6}$ Parece claro que María Moliner ha tenido en cuenta la frecuencia de uso de los verbos transitivos con respecto a los usos pronominales o intransitivos, o a la inversa, por lo que alteraba conscientemente el orden de presentación de las acepciones, lo cual no ocurre en los casos asistemáticos del DRAE.
} 


\section{Engordar:}

1. intr. y menos frec., prnl. Ponerse gordo o más gordo. $\bigcirc$ tr. Poner gordo o más gordo a una persona o animal.

No obstante, al tratar el verbo adelgazar (acepciones 1 y 2) ya no se opta por la distinción entre acepciones y subacepciones, sino que se presentan dos acepciones, una para cada construcción, sin incluir ejemplos de uso, tal y como vemos en el ejemplo:

\section{Adelgazar:}

1. tr. Poner una cosa más delgada. 2. intr. y menos frec., prnl. Hacerse o ponerse delgado o más delgado.

A su vez, a estos dos criterios hay que añadir un tercero en el que se incluyen ambas construcciones bajo una misma definición que las engloba, introduciendo entre corchetes la marca pronominal. De este modo, recaerá en el lector la tarea de tener en cuenta las marcas de la definición para el uso pronominal del verbo, y su omisión cuando se trate de la construcción biactancial. Es lo que ocurre en el caso de avinagrar (acepción 1) o de quebrar (acepción 1), como vemos en los ejemplos que siguen:

\section{Quebrar:}

1. tr. y prnl. Romper[se] o rajar[se] una cosa frágil al hacer fuerza en ella.

\section{Avinagrar:}

1. tr. y prnl. Convertir[se] el vino en vinagre. 
Ya por último, constatamos que el artículo correspondiente al verbo adecentar no refleja su uso pronominal, creemos que con buen criterio, ya que el DUE solo incluye la definición que se corresponde con la variante transitiva.

Se observa, pues, que son varios los criterios a seguir por ambas obras, aunque consideramos que en el DUE se reflejan en mayor medida las posibilidades constructivas de los verbos de cambio, así como las variantes semánticas que sufren, a pesar de no existir un criterio homogéneo en su tratamiento.

\section{Diccionario 'Coruña’ de la lengua española actual}

Por su parte, el DCLEA, en búsqueda de mayor precisión y exactitud, se presenta como el diccionario más completo de los hasta aquí vistos. En esta obra se amplía en gran medida la información sintáctica con respecto a las obras anteriores, aspecto que, aplicado a las categorías verbales, permite mostrar la subcategoría de los verbos, su comportamiento sintáctico, la naturaleza semántica del sujeto y del objeto directo, la posibilidad de uso pronominal, los cambios que cada construcción implica en relación con otras, etc. y que, por lo tanto, se presenta como muy útil y necesario a la hora de abordar la definición de los verbos de cambio.

A su vez, la inclusión de autoridades procedentes de textos reales permite constatar el uso contextual de cada una de las variantes construccionales así como dar testimonio real de su uso.

$\mathrm{Si}$ atendemos, por tanto, a los criterios que utiliza el DCLEA para llevar a cabo la separación de acepciones en 
los verbos, comprobamos que uno de ellos es el relativo a su configuración actancial, esto es, el contexto sintácticosemántico de que estos forman parte en su funcionamiento real en el discurso. De tal manera, se considera que se trata de significados o acepciones distintas de un vocablo cuando este forma parte en cada una de ellas de paradigmas o campos léxicos diferentes. Por el contrario, se tratará de meras subacepciones cuando no se produzca cambio de paradigma. En el caso de los verbos, solo cuando la estructura actancial cambia, se produce realmente un cambio de acepción, pero no cuando los argumentos o actantes se comportan sintácticamente de un modo distinto.

Teniendo en cuenta esto, observamos que en el caso de los verbos que aquí estamos analizando, y tal y como observamos en los ejemplos de 1, las construcciones de 1.a. y 1.c. presentan la siguiente estructura actancial: V (A1, A2), cuyos actantes funcionan como sujeto y objeto directo, respectivamente. Por su parte, las construcciones 1.b y 1.d. poseen la siguiente estructura actancial: V (A2, (A1)), cuyos actantes funcionan como sujeto y complemento preposicional, respectivamente.

Ambas construcciones presentan un mismo actante, A2, que en la construcción transitiva es objeto directo y en la pronominal, por su carácter intransitivo, pasa a sujeto. Se hace patente que los verbos de cambio en su construcción transitiva presentan un actante causa que desempeña la función sintáctica de sujeto y, en la construcción intransitiva o pronominal, la de complemento preposicional, cuando aparece. Por su parte, la entidad paciente funciona en el plano sintáctico como objeto directo de la construcción 
transitiva y como sujeto en la construcción pronominal o intransitiva.

Podemos decir, entonces, que lo que hay en ambas construcciones es un simple cambio de diátesis en el verbo, pues este sigue representando la misma unidad léxica, ya que se trata de la misma estructura actancial. En el caso de adelgazar, tanto la construcción pronominal como la transitiva forman parte del campo de la pérdida de peso o de grosor, por lo tanto, del mismo paradigma.

Por ello, en esta obra se opta por situar como acepciones las construcciones transitivas del verbo y como subacepciones las relativas a la construcción pronominal media, que implican simplemente una variante de aquellas.

Así, mediante la fórmula 'pasando a sujeto el objeto directo' más una nueva definición se homogeneiza la redacción de ambas acepciones reflejando la relación existente entre ellas y mostrando la variación tanto contextual como de significado en el paso de la construcción biactancial a la pronominal, tal y como se observa en la subacepción 1d) del artículo de ahumar:

\section{Ahumar:}

1. tr. $[\sim$ alguien o algo $<$ p.e. el fuego $>$ (suj.) a una persona o una cosa (od.)] Exponerla o someterla a la acción del humo.

La colocación de las colmenas debe permitir que el abejero maneje la colonia por detrás de la colmena. Esto [...] le permite al abejero ahumar la colonia antes de que se alerten las abejas guardianas de la entrada (El Apiario).

d) Pasando a suj. el obj. directo, 'recibir los efectos del humo'. 
Si la casa era serrana, no faltaban los jamones ahumándose o algunos cuyes corriendo por allá y por acá (La cocina, Olivas, s/p).

- Particularmente, 'adquirir una comida sabor a humo por efecto de éste o por haberse quemado'. Como siempre estuve acostumbrada a cocinar con estufas de gas, la primera vez (y también la segunda) que hice un arroz en estufa eléctrica ${ }^{\star} \mathrm{se}^{\star}$ me ${ }^{\star}$ ahumó ${ }^{\star}$ (pusorock. com/21-05-2012).

De igual modo, esto posibilita que se registre el menor número posible de acepciones siguiendo el "principio de simplicidad descriptiva”.

Si analizamos el tratamiento dado por esta obra a los 11 verbos anteriormente enunciados, comprobamos que en todos los casos el DCLEA registra una única acepción que engloba ambas construcciones, situando como subacepción o variante la construcción pronominal media, a la que se le añade una nueva definición, tal y como vemos en el caso de quebrar (acepción 1):

\section{Quebrar:}

1. tr. [ alguien o algo (suj.) una cosa dura o rígida (od.)] Romperla con estrépito o violencia.

Supo que en el momento en que quebró una pata de cangrejo y oyó descorchar una botella de champaña, concluía una fase de su vida y otra se anunciaba, más plena, más libre (La vida, Pitol, 35).

a) Por extensión, 'romper en general. Puede referirse también a lo inmaterial.

No obstante, advirtió que lo que puede quebrar la confianza "no son los desacuerdos, sino los incumplimientos" (La Vanguardia, $12 / 10 / 94)$. 
b) Pasando a suj. el obj. directo, 'romperse'.

Aquel día, el céltico saltó al campo para disputar un encuentro amistoso contra el Betis, con motivo del Memorial Quinocho, y al poco sintió que la rodilla izquierda se le quebraba (Faro, 20/02/01).

$\mathrm{Y}$ puesto que un verbo con los mismos argumentos ofrece posibilidades sintácticas diferentes dentro de una misma acepción, el diccionario las registra todas mediante una aclaración al respecto después de la definición. Así, en el caso de amargar, que aquí reproducimos sin autoridades, se reflejan tanto las posibilidades constructivas, como las variaciones de significado:

Amargar:

1. tr. [ alguien (suj.) una comida o bebida (od.) < a otra persona > (oi.) $<$ con algo $>$ (cp.)]. Hacer que se vuelva de sabor amargo. El compl. prep. puede actuar como suj. A su vez el obj. directo puede ser, en vez de la comida o bebida, el sabor de ésta. a) prnl. Pasando a suj. el obj. directo, 'volverse amargo, tomar ese sabor'. b) intr. Siendo suj. la comida o bebida, 'tener sabor amargo'.

Como se evidencia, la subacepción supone siempre una nueva definición, aunque esta sea entendida como una particularización de la primera o general, correspondiente a la acepción.

Las subacepciones implican una definición más específica que la acepción más general en la que se incluye, por lo que a veces se hace necesario indicar el contexto propio de la nueva construcción, tal y como se observa en el apartado correspondiente a la subacepción de 1a) en el artículo de 
templar, en el que se especifica el contorno por tratarse ya solo de una definición que afecta al 'tiempo':

\section{Templar:}

1. tr. [ alguien (suj.) una cosa fría o caliente en alto grado (od.) <con otra de temperatura contraria $>$ (cp.)]. Hacer que se ponga templado, esto es, a una temperatura intermedia, entre fría y caliente. El compl. prep. puede pasar a suj.

Se apareció el primer día y con desenvoltura llenó de agua la tina de madera, luego hirvió otro par de baldes y templó el agua (De modo, Menéndez, 117).

a) prnl o intr Pasando a suj. el obj. directo, 'pasar a estar templado'.

Remonta los ríos cuando la temperatura de las aguas se templa, y permanece en ellos hasta que desova y vuelve luego al mar (El País, 02/05/80).

- Dicho del tiempo, 'ponerse a una temperatura ni alta ni baja'.

En abril, cuando el tiempo empezaba a templar, acogiendo caracoles $y$, hace apenas un par de meses, en otoño, llenando el perol de moras grandesyjugosas, queluego tomaba de postretodala familia(Efímero).

Ocurre lo mismo en la subacepción 1a) de adecentar, en la que se hace necesario especificar que solo las personas 'se arreglan debidamente.

\section{Adecentar:}

1. tr. [ alguien (suj.) a otra persona o cosa (od.)] Hacer que esté limpia y en orden.

Es un alcalde con voz propia. Se ocupa mucho de los ancianos [...] y adecenta lo que puede el barrio antiguo de la ciudad (Los hombres, Gironella, 45). 
a) prnl. Dicho de una persona, 'arreglarse debidamente'.

Me adecentaré un poco, no me gusta que papá me vea tan descuidada (La vida, Vázquez, 106).

A la vista de lo expuesto hasta aquí puede deducirse que una de las aportaciones más interesantes del DCLEA es su información sintáctica, que constituye, sin duda, una parcela imprescindible a la hora de abordar la definición de los verbos y que en muchas obras lexicográficas estaba olvidada.

Consideramos que esta última obra supera muchos de los desajustes e imprecisiones que hemos encontrado en otras obras, refleja la relación entre los distintos usos de una misma unidad léxica y confiere homogeneidad a la hora de redactar.

\section{Conclusiones}

El objetivo de este análisis ha sido acercarnos al tratamiento lexicográfico dado a los verbos de cambio en tres diccionarios generales monolingües del español, lo que nos ha permitido mostrar tanto los aciertos como algunos de los desajustes gramaticales en que pueden incurrir los repertorios lexicográficos.

Tal y como se ha evidenciado, la importancia de tener en cuenta la estructura actancial para la definición de los verbos evitaría ciertas inexactitudes semánticas y sintácticas y permitiría al usuario comprender las distintas posibilidades construccionales de un determinado vocablo. Es necesario hacer explícitos cada uno de los matices semánticos que ex- 
presan los verbos al variar de estructura actancial; solo de esta forma es posible entender el uso que un verbo tiene en el discurso real.

\section{Bibliografía}

Conde, María Eugenia (2015), "La estructura argumental de los verbos de cambio de estado para su tratamiento lexicográfico”, en Ma José Domínguez, Xavier Gómez y Carlos Valcárcel (eds.), Lexicografía de las lenguas románicas, Berlín, Walter de Gruyter, pp. 111-123.

Coronado, María Luisa et al. (1994), A fondo. Curso superior de español para extranjeros, Madrid, SGEL.

Cuervo, Rufino José (1953), Diccionario de construcción y régimen de la lengua castellana, I, Santafé de Bogotá, Instituto Caro y Cuervo.

Moliner, María (1977 [2007]), Diccionario de uso del español, $3^{\text {a }}$ ed., Madrid, Gredos.

Oreal, Ma Jesús (2008), "El tratamiento de verbos con valor 'pseudo-copulativo' que expresan cambio en los repertorios lexicográficos didácticos del español”, en Dolores Azorín et al. (eds.), El diccionario como puente entre las lenguas y culturas del mundo. Actas del II Congreso Internacional de Lexicografía Hispánica, Alicante, Biblioteca Virtual Miguel de Cervantes, pp. 367-372.

Porroche, Margarita (1988), Ser, estar y verbos de cambio, Madrid, Arco-Libros.

Porto Dapena, José Álvaro (2008), El Diccionario 'Coruña' de la lengua española actual: planta y muestra, A Coruña, Universidade da Coruña. 
Real Academia Española (2001), Diccionario de la lengua española, 22a ed., Madrid, Espasa-Calpe.

Veleiro, Ana (2005), "El tratamiento de los verbos de cambio de estado físico y psíquico en la última edición del "Diccionario de la Lengua Española" de la Real Academia Española", RILCE: Revista de Filología Hispánica, 21, 2, pp. 281-301. 
